\title{
Microbial dynamics in upflow anaerobic sludge blanket (UASB) bioreactor granules in response to short-term changes in substrate feed
}

\author{
Correspondence \\ Weiwen Zhang \\ Weiwen.Zhang@asu.edu
}

Received 26 November 2009

Revised 27 April 2010

Accepted 28 April 2010

\author{
William P. Kovacik, Jr, ${ }^{1} \dagger$ Johannes C. M. Scholten, ${ }^{1}$ David Culley, ${ }^{1}$ \\ Robert Hickey, ${ }^{2}$ Weiwen Zhang ${ }^{1} \ddagger$ and Fred J. Brockman ${ }^{1}$ \\ ${ }^{1}$ Microbiology Department, Pacific Northwest National Laboratory, Richland, WA 99354, USA \\ ${ }^{2}$ Ecovation, Inc., Victor, NY 14564, USA
}

The upflow anaerobic sludge blanket (UASB) reactor is a microcosm for the methanogenic degradation of organic matter in anaerobic environments, and depends on the auto-formation of dense 3D biofilms of 1-3 $\mathrm{mm}$ in diameter, referred to as granular sludge (biogranules). Past research has shown that UASB and other methanogenic reactors are extremely stable functionally, but the underlying basis of the functional stability is not well understood. In this study, microbial dynamics in the communities residing in UASB biogranules were analysed to determine responses to short-term perturbations (change in reactor feed). The reactor was fed with simulated brewery wastewater (SBWW) for 1.5 months (phase 1), acetate/sulfate for 2 months (phase 2), acetate alone for 3 months (phase 3) and then a return to SBWW for 2 months (phase 4). Analysis of 16S rRNA, methanogen-associated $m c r A$ and sulfate reducer-associated $d s r A B$ gene-based-clone libraries showed a relatively simple community composed mainly of the methanogenic archaea (Methanobacterium and Methanosaeta), members of the green non-sulfur (Chloroflexi) group of bacteria and Syntrophobacter, Spirochaeta, Acidobacteria and Cytophaga-related bacterial sequences. The $m c r A$ clone libraries were dominated throughout by Methanobacterium- and Methanospirillum-related sequences. Although the reactor performance remained relatively stable throughout the experiment, community diversity levels generally decreased for all libraries in response to a change from SBWW to acetate alone feed. There was a large transitory increase noted in $16 \mathrm{~S}$ diversity at the 2 month sampling on acetate alone, entirely related to an increase in bacterial diversity. Upon return to SBWW conditions in phase 4, all diversity measures returned to near phase 1 levels. Our results demonstrated that microbial communities, even highly structured ones such as in UASB biogranules, are very capable of responding to rapid and major changes in their environment.

\section{INTRODUCTION}

The majority of microbial life in nature exists as groups of interdependent, highly cooperative and functionally

tPresent address: Pegasus Technical Services Inc., Cincinnati, $\mathrm{OH}$ 45224, USA.

‡Present address: Center for Ecogenomics, Biodesign Institute, Arizona State University, PO Box 876501, Tempe, AZ 85287-6501, USA.

Abbreviations: ATM, acetotrophic methanogens; COD, chemical oxygen demand; GNS, green-non-sulfur; HTM, hydrogenotrophic methanogens; OTU, operational taxonomic unit; SBWW, synthetic brewery wastewater; UASB, upflow anaerobic sludge blanket.

The GenBank/EMBL/DDBJ accession numbers for the 16S rRNA gene sequences are AY940120.1-AY940126.1, AY899826.1-AY899846.1, AY910845.1-AY910860.1, AY903645.1-AY903697.1, AY937274.1AY937285.1 and AY929594.1-AY929610.1.

Three supplementary figures and six supplementary tables are available with the online version of this paper. distinct organisms living in spatially well-defined communities such as biofilms and flocs (Davey \& O'Toole, 2000; Sekiguchi et al., 2001a; Briones \& Raskin, 2003). The close association of different types of organisms offers advantages to the individuals living in the community: protection from toxins, predators and invasive species, the concentration and sequestering of limiting nutrients (for example $\mathrm{N}$ and $\mathrm{P}$, metals), the acquisition of new genetic traits by horizontal gene transfer, plus the ability to derive energy and carbon from recalcitrant or complex substrates, overcoming thermodynamic barriers to utilize compounds in syntrophic fashion for the good of the whole community. An example of a highly structured community of micro-organisms is found in upflow anaerobic sludge blanket (UASB) reactors, the most widely used process configuration in the world for anaerobic treatment of industrial wastes (Lettinga, 1995; Sekiguchi et al., 2001a; Díaz et al., 2003). The UASB reactor is a microcosm for 
the methanogenic degradation of organic matter in anaerobic environments, and depends on the auto-formation of dense 3D biofilms of $1-3 \mathrm{~mm}$ in diameter, referred to as granular sludge (biogranules). The composition of the bacterial communities residing in biogranules depends on the waste being treated, but generally consists of two or three distinct trophic levels of organisms, such as fermentative organisms, fatty acid-oxidizing bacteria (syntrophs) and acetogenic bacteria (Schink, 1992a, 1997; Briones \& Raskin, 2003). Past research has shown that UASB and other methanogenic reactors are extremely stable functionally (Fernandez et al., 1999; Zumstein et al., 2000; LaPara et al., 2002; Pender et al., 2004), but the underlying basis of the functional stability is not well understood.

The purpose of our study was to determine the effect of short-term perturbations (change in reactor feed) on the highly structured archaeal/bacterial communities residing in UASB biogranules. Our hypothesis was that the complexity and diversity of organisms should decrease in response to shifting from a more complex to a simple feeding regiment, due to the elimination of a certain trophic level. But confounding this issue is the relative physical stability and integrity of the biogranules, and the ability of fermenters and acetogens/syntrophs and other bacteria to grow by utilizing decaying biomass or by switching to alternative (as of yet unknown) energyyielding metabolisms. The highly organized structure of the biogranules is potentially beneficial for stable community function and reactor performance, but perhaps a detriment for responding to short-term change or perturbation. To test the hypothesis, a 7 l working volume UASB reactor was seeded with biogranules from a full-scale reactor treating brewery wastewater and was fed with different substrates. At the end of each perturbation, granules were sampled and DNA was extracted for clone library analysis using (i) the 16S rRNA gene with universal primers, (ii) methanogen-associated methyl Co-M reductase gene $(m c r A)$ and (iii) sulfate reducer-associated dissimilatory (bi)-sulfite reductase $(\operatorname{ds} r A B)$ genes, to focus on the functional genes of two groups most likely to be affected by the changes in substrate feed. Our results showed that microbial communities, even highly structured ones such as in UASB biogranules, are very capable of responding to rapid and major changes in their environment.

\section{METHODS}

Reactor operation. The 71 UASB reactor was set up and seeded with granules obtained from an Anheiser Busch brewery facility in Baldwinsville, NY. The system was initially fed a synthetic brewery wastewater (SBWW) developed in prior work (Wu et al., 1995). The approximate contribution to the chemical oxygen demand (COD) was due to three compounds: ethanol $70 \%$, propionate $15 \%$ and acetate $15 \%$. Nitrogen, phosphorus and sulfur were added at a ratio of COD/N/P/S of $100: 1: 0.2: 0.2$. Nitrogen, phosphorus and sulfur were supplied as urea, sodium hexametaphosphate and ferrous sulfate, respectively. Calcium and magnesium were added at
$10 \mathrm{mg}^{-1}$ for ionic balance. Dechlorinated tap water was used as the feed to which the substrates and nutrients were added via metering pumps. Trace metals essential for maintaining healthy anaerobic populations were provided via pulse addition twice per week. The reactor was operated at $35{ }^{\circ} \mathrm{C}$ with $\mathrm{pH}$ controlled between 6.6 and 6.8 using an online $\mathrm{pH}$ controller, which sends a signal to deliver a concentrated sodium bicarbonate solution. The feed (influent) COD concentration was maintained at $5600 \mathrm{mg} \mathrm{l}^{-1}$ for all periods. This resulted in an applied organic loading rate of approximately $12 \mathrm{~kg} \mathrm{COD} \mathrm{m}^{-3}$ per day. The system was operated to foster progressively less complex microbial communities by changing feed from SBWW, to acetate only plus the sulfur supplied as sulfate $(0.35 \mathrm{mM})$, to acetate only with sulfur supplied as sulfide. To test our research hypothesis, the UASB reactor was seeded with biogranules that were fed with different substrates according to the following strategy. In phase 1 , growth was on a mixture of $75 \%$ ethanol/15\% propionate/15\% acetate/minimal sulfate (SBWW) for 1.5 months. In phase 2 , the feed was switched to acetate plus minimal sulfate for 2 months, followed by phase 3 growth on acetate alone for 3 months (with a 'mid' sampling point at 2 months and 'late' sampling point at 3 months). Finally, in phase 4 , the reactor was returned to the initial SBWW feed for 2 months. At the end of each perturbation, granules were sampled and DNA was extracted for clone library analysis.

DNA isolation, PCR, cloning and sequencing. Total DNA was isolated from approximately $200 \mathrm{mg}$ granules using the UltraClean soil DNA kit according to the manufacturer's protocol (MoBio Laboratories), except initial homogenization was performed using a mini-beadbeater- 8 homogenizer (Biospec Products) on homogenization setting for $3 \mathrm{~min}$. The concentration of DNA was determined by using a NanoDrop ND-1000 spectrophotometer (NanoDrop) and purity was checked by agarose gel electrophoresis. Twenty-five nanograms of genomic DNA was amplified in $25 \mu \mathrm{l}$ PCR tubes utilizing $250 \mu \mathrm{M}$ dNTPs, $0.5-2.0 \mu \mathrm{M}$ of each primer, $1 \mathrm{U}$ Platinum Taq DNA Polymerase and $1 \times$ reaction buffer (Invitrogen). A total of 35 cycles was employed, consisting of a $1 \mathrm{~min}$ denaturation step at $95{ }^{\circ} \mathrm{C}, 1 \mathrm{~min}$ annealing step and $1.5 \mathrm{~min}$ extension at $72{ }^{\circ} \mathrm{C}$ for each cycle, with an initial denaturation at $95{ }^{\circ} \mathrm{C}$ for $10 \mathrm{~min}$ and final extension at $72{ }^{\circ} \mathrm{C}$ for $10 \mathrm{~min}$. For $16 \mathrm{~S}$ and $d s r A B$ PCR, a touchdown PCR protocol was employed (Muyzer et al., 1993), decreasing the annealing temperature by $0.5{ }^{\circ} \mathrm{C}$ per cycle from 65 to $52{ }^{\circ} \mathrm{C}$ for 20 cycles, followed by 10 cycles at $52{ }^{\circ} \mathrm{C}$. For $m c r A$ PCR, 35 cycles at $52{ }^{\circ} \mathrm{C}$ constant was used for the annealing conditions. The primers used for amplification by PCR are shown in Table 1 . The forward primers incorporate a G-C-rich clamp (Sheffield et al., 1989), so that the PCR products can be utilized in a future DGGE study. The Arch/ Bact 519FC primer was changed from the original universal primer published by Lane et al. (1985) to be more encompassing for the methanogenic archaeal and bacterial species expected in the granules, and less so for eukaryotic organisms. PCR products were purified using a QiaQuick gel extraction kit (Qiagen) and ligated into pSTBlue-1 vector using the Novagen perfectly blunt cloning kit (EMD Biosciences). The positive clones were sequenced by ACGT Inc. using T3 and T7 primers. The double-stranded 750-800 base DNA sequences were obtained for all $m c r A$ and $16 \mathrm{~S}$ clones. For $d s r A B$ clones with insert of $\sim 1.9 \mathrm{~kb}$, the centre gap was filled with custom primers. The raw sequencing data were analysed using the Lasergene software package from DNASTAR. The sequences with less than $3 \%$ difference at DNA level were treated as the same operational taxonomic unit (OTU). Over 600 DNA sequences were analysed in this study.

Sequence alignment and phylogenetic analysis. For 16S rRNA genes, the sequences were analysed using the programs from the Ribosomal Database Project II (RDP) (http://rdp.cme.msu.edu/index. jsp) for possible chimeras. Sequences of $16 \mathrm{~S}, \mathrm{mcr} A$ and $d s r A B$ were 
Table 1. Primers used for PCR

\begin{tabular}{|c|c|c|c|c|}
\hline Name & Primer type & Sequence $\left(5^{\prime}-3^{\prime}\right)$ & Specificity & Reference \\
\hline $\begin{array}{l}\text { Arch/Bact } \\
\text { 519FC }\end{array}$ & $\begin{array}{l}\text { 16S rDNA, forward } \\
\text { clamped }\end{array}$ & $\begin{array}{l}\text { CAGC(AC)GCCGC- } \\
\text { GGTAA(TC)AC* }\end{array}$ & $\begin{array}{l}\text { Archaea/bacteria specific, modified } \\
\text { from original for this paper }\end{array}$ & Lane et al. (1985) \\
\hline Univ1392r & $16 \mathrm{~S}$ rDNA, reverse & ACGGGCGGTGTGT(AG)C & Universal & \\
\hline ME1FC & $\begin{array}{l}m c r A, \text { forward } \\
\text { clamped }\end{array}$ & $\begin{array}{l}\text { GC(AC)ATGCA(AG)AT- } \\
(\text { ACT)GG(AT)ATGTC* }\end{array}$ & $\begin{array}{l}\text { Methyl CoM reductase, } m c r A \text {, } \\
\text { methanogen specific }\end{array}$ & Hales et al. (1996) \\
\hline ME2R & $m c r A$, reverse & $\begin{array}{l}\text { TCAT(GT)GC(AG)TAGTT- } \\
\text { (AGT)GG(AG)TAGT }\end{array}$ & & \\
\hline $\begin{array}{l}\text { DSR1FC } \\
\text { DSR4R }\end{array}$ & $\begin{array}{l}d s r A B, \text { forward clamped } \\
d s r A B, \text { reverse }\end{array}$ & $\begin{array}{l}\text { AC(GC)CACTGGAAGCACG* } \\
\text { GTGTAGCAGTTACCGCA }\end{array}$ & $\begin{array}{l}\text { Dissimilatory sulfite reductase, } \\
d s r A B, \text { sulfate reducing } \\
\text { bacteria (SRB)-specific }\end{array}$ & $\begin{array}{l}\text { Wagner et al. } \\
\text { (1998) }\end{array}$ \\
\hline
\end{tabular}

${ }^{\star}$ Forward G-C-rich clamp added to 5' end, sequence: CGCCCGCCGCGCCCCGCCCGGCCCGCCGCCCCCGCCCGGG (Shigematsu et al., 2003).

then aligned using the ARB shareware program (version 2.5b) (Ludwig et al., 2004) (http://www.arb-home.de/). Phylogenic trees were generated using distance (ARB and PHYLIP), parsimony (PHYLIP DNAPARS) and maximum-likelihood (fastDNAml) methods, and bootstrapping (neighbour joining and/or parsimony) was performed. Branches with less than $50 \%$ bootstrapping values were collapsed into higher groupings. The OTUs were then determined based on a $3 \%$ divergence cut-off for an individual 'species' OTU. All DNA sequences have been submitted to the NCBI GenBank database.

Statistical analysis. Rank-based Spearman correlation coefficient was computed to indicate the microbial community similarity. In addition, the correlation was tested and a $P$-value was calculated to indicate the significance level of the correlation. The analysis was performed with SAS software (Version 9). The Shannon-Wiener index method was used to determine diversity (Shannon \& Weaver, 1948). Two measures were employed to estimate the extent of coverage of diversity in our clone libraries, one based on log normal distribution (Mullins et al., 1995) and another based on rarefaction analysis using a RarefactWin shareware program (http://www.uga. edu/ strata/software/Software.html) (Hurlbert, 1971).

\section{RESULTS}

\section{Reactor performance}

The overall performance of the 71 UASB bioreactor is shown in Fig. 1. COD removal efficiency was generally between 97 and $100 \%$ of substrate input, and gas production ranged between 37 and 50 litres per day on average. It is important to note that throughout the entire experiment, no macro-level physical differences were noted in biogranule appearance; they were generally round or elliptical in shape, $0.5-3 \mathrm{~mm}$ in diameter and black in colour.

\section{Dynamics of clone libraries}

16S rRNA clones. 16S rRNA library analysis revealed a mixed community of archaeal and bacterial types (Supplementary Table S1, available with the online version of this paper). Twenty-three distinct OTUs were detected based on a $3 \%$ sequence cut-off. Methanogens dominated the clone library at all time points (Supplementary Fig. S1), representing nearly $75 \%$ of all clones analysed during the experiment. Methanogenic OTUs fell into two groups, those related to Methanobacterium subterraneum (OTU I-III), a halotolerant methanogen isolated from deep granitic groundwater, capable of growth on hydrogen or formate (Kotelnikova et al., 1998), and those related to Methanosaeta sp. (OTU IV-V), in which known species are capable of methanogenic growth on acetate, but not hydrogen or formate. The distribution of methanogenic clones changed during the course of the experiment. During initial growth on SBWW, OTUs related to Methanobacterium represented $52 \%$ of the clones analysed, while those related to Methanosaeta sp. represented only $26 \%$ of clones. After the change in feed to acetate plus sulfate, both clone types were equally represented, at $38 \%$ of total clones. During the transition to acetate-alone feed, clone numbers related to Methanosaeta continued to rise, while those related to Methanobacterium declined, eventually

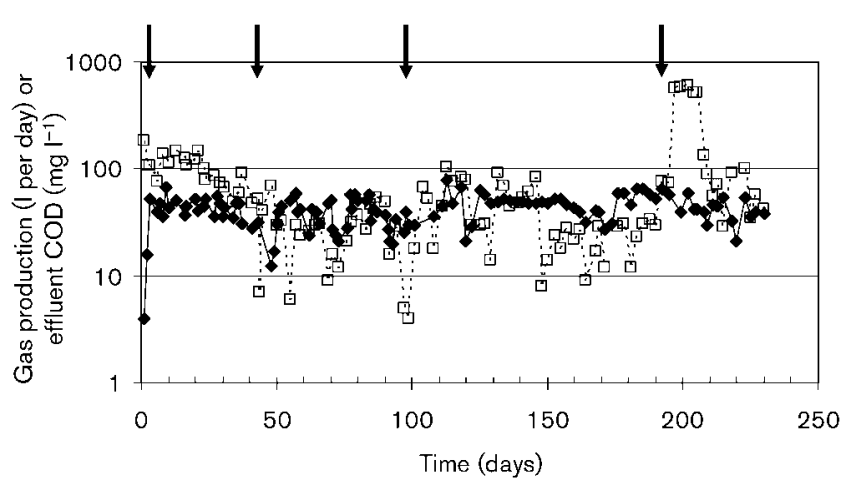

Fig. 1. Reactor performance. Results for gas production (I per day; $\diamond)$ and effluent COD ( $\left.\mathrm{mg} \mathrm{I}^{-1} ; \square\right)$ during the course of the experiment. Arrows (from left to right) indicate major changes to substrate feed: phase 1, growth on SBWW; phase 2 , change to acetate plus minimal sulfate; phase 3 , change to acetate alone; and phase 4 , regrowth on SBWW. 
resulting in a 59 to $27 \%$ distribution, respectively. Upon return to SBWW feeding, clones related to Methanosaeta continued to dominate, representing $49 \%$ of clones, while those related to Methanobacterium represented only $22 \%$ of the clones.

The second most abundant group (11\% of total clones) was related to the green-non-sulfur (GNS) group of
Bacteria (phylum Chloroflexi). Occurrences of individual OTUs fluctuated in non-discernible patterns throughout the experiment, with the group representing over $28 \%$ of total clones analysed during the 2 month sampling on acetate alone (mid). Unlike the rather monophyletic Archaea, the GNS group comprised many unique OTUs spanning an extensive phylogenetic distance (Fig. 2). Deltaproteobacteria related to Syntrophobacter wolinii were

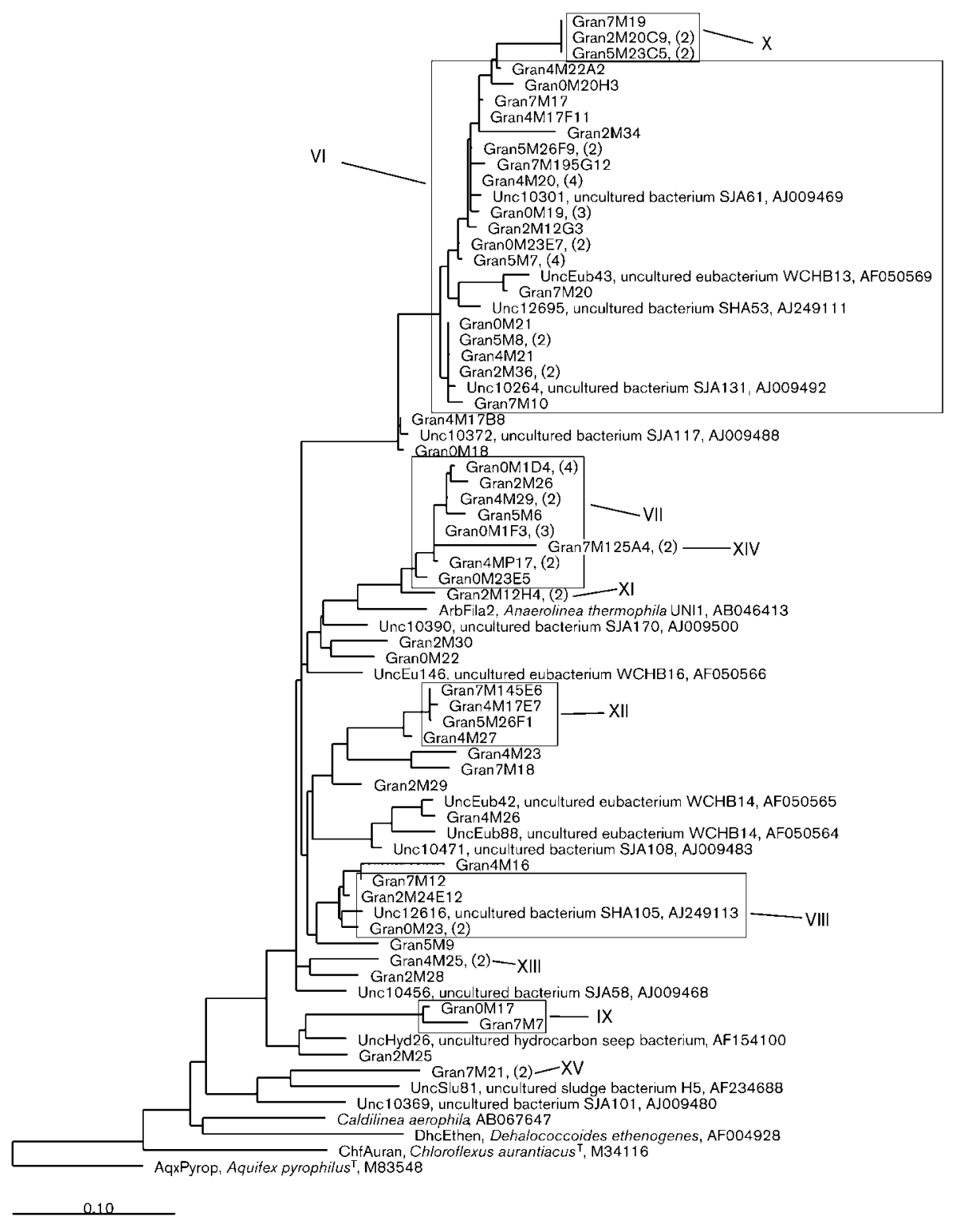

Fig. 2. Phylogenetic diversity of the green-non-sulfur (GNS) group of bacteria in biogranules. The maximum-likelihood tree is based on full-length $(1400+$ bp) ARB-aligned sequences, with partial 16S rRNA gene biogranule clone sequences inserted into the tree using the maximum-parsimony option within ARB. OTU groups based on $3 \%$ cut-off are labelled in Roman numerals (group numbers correspond with Supplementary Table S1). Biogranule clone names refer to the sampling point (4M is a 4 month clone), with the number of closely related clones shown in parentheses. The tree was constructed with the 16S rRNA gene of Aquifex pyrophilus as the out-group and a filter in ARB (bac_rr5_june03) that excluded alignment positions with sequence ambiguity or missing data. The confidence of branch points was determined by three separate analyses (maximumlikelihood, evolutionary distance and maximum-parsimony). The scale bar indicates $10 \%$ estimated sequence divergence. 
detected at most time points, but were most prevalent during the 2 month sampling on acetate alone, and during regrowth on SBWW (Supplementary Fig. S2). S. wolinii grows syntrophically on propionate in combination with a hydrogen-utilizing methanogen (Boone \& Bryant, 1980). Clones related to Bacteroides, Spirochaetes and Acidobacteria were represented as well, but none was greater than $5 \%$ of the total clones analysed (Supplementary Fig. S3). Similar to the GNS group, clones from these groups fluctuated in number but were most numerous during the 2 month sampling point on acetate alone.

mcrA clones. Analysis of the $m c r A$ clone library revealed seven distinct clone OTUs relating to two classes of Archaea, the class Methanobacteria (OTU I-III) and the class Methanococci (OTU IV-VII) of the Euryarchaeota phylum within the domain Archaea (Supplementary Table S2). The distribution of individual OTUs related to Methanobacteria varied by treatment, with OTU I being the most numerous, and OTUs II and III fluctuating by treatment. In total, the group represented the majority of clones in the $m c r A$ library, corresponding to at least twothirds of the total clones for each treatment. The exception was the 3 month sampling on acetate alone, where clones related to Methanobacteria were approximately equal to those related to Methanococci. OTUs IV-VII of the class Methanococci were more divergent and each was most closely related to different organisms on the database. OTU IV, most closely related to Methanospirillum hungatei (Ferry et al., 1974), was the most numerous clone of this type for most treatments, with the others varied by treatment. In general, Methanospirillum-related clones were fewer in number than those related to the Methanobacteria-related clones.

dsrAB clones. Analysis of the $d s r A B$ clone library revealed clones relating to 11 distinct OTUs, all related to incomplete oxidizing sulfate-reducing bacteria (Supplementary Table S3). The majority of clone types were closely related to Desulfovibrio species (OTU I-VI), representing $50 \%$ of all clones sampled. These clones were most numerous during the first two phases of the experiment, growth on SBWW and acetate plus sulfate, and less numerous during growth on acetate alone or during regrowth on SBWW. The second most representative clone type was closely related to Desulfomonile tiedjei (OTU VII), but didn't appear in our libraries until growth on acetate alone, in which it represented two-thirds of clones analysed during that treatment. The numbers for this OTU remained high during the regrowth on SBWW, representing $58 \%$ of clones sampled. Finally, there were several OTUs related to Desulfotomaculum species (OTU VIII-X), which were most prevalent during phase 1 growth on SBWW, representing over $50 \%$ of the clones analysed. Upon transition to the simpler feeding regimens, these clones decreased in number and were not observed with growth on acetate or regrowth on SBWW.

\section{Comparison of community diversity and composition}

The $\log$ normal function indicated greater than $85 \%$ coverage for all libraries (range 85-98\%), and the plateau shape of many of the curves indicated that the majority of the diversity was captured by our cloning effort (Tipper, 1979) (Fig. 3). The changes in community diversity, as indicated by the Shannon-Wiener diversity index, in the biogranules during the experiment are shown in Fig. 4. During the initial transition from SBWW to acetate/sulfate, there was a slight increase noted for diversity in $16 \mathrm{~S}$ clones, while $m c r A$ and $d s r A B$ diversity decreased slightly. During the second transition to the acetate-alone feed, major changes in community structure occurred. At the 2 month sampling point on acetate alone (mid), the diversity of the $16 \mathrm{~S}$ rRNA gene community rose dramatically (nearly $150 \%$ increase over initial phase 1 values), almost entirely as the result of an increased number of bacterial OTU (Fig. 4, bacterial component of the Shannon-Wiener index). At this sample point, diversity levels for the $\mathrm{mcr} A$ gene continued to decrease, paralleling changes noted for methanogens by $16 \mathrm{~S}$ rRNA gene data (Fig. 4, archaea component of the Shannon-Wiener index). Unfortunately, we were unable to amplify DNA from the biogranules by PCR using $d s r A B$ primers for this sampling point, despite repeated attempts. Since there were species present in our 16S libraries for this time point that should contain $d s r A B$ genes, for example those related to the deltaproteobacterium $S$. wolinii, it was unclear why we were unable to amplify DNA from this sample. For the 3 month sampling on acetate alone (late), another dramatic shift in diversity occurred, with total $16 \mathrm{~S}$ rRNA gene diversity dropping nearly $40 \%$ below phase 1 levels on SBWW. The diversity values for all three genes were nearly identical during this sampling (at approximately 1.61.7). After a return to SBWW in the final phase of our experiment, diversity measures for all groups increased to almost phase 1 levels. The similarity of microbial communities between different phases was evaluated by rankbased Spearman correlation coefficient for 16S rRNA, mcrA and $d s r A B$ libraries (Supplementary Tables S4, S5 and S6).

\section{DISCUSSION}

In this study, we targeted the $16 \mathrm{~S}$ rRNA, $m c r A$ and $d s r A B$ genes to investigate the effect of short-term changes in substrate feed on the microbial dynamics of the highly structured archaeal/bacterial communities residing in methanogenic UASB biogranules. At the macro-level, there were no apparent differences in granule appearance, size or colour or in overall reactor performance during growth on the different substrate feeds. Even though the feed transitioned from a relatively complex one of ethanol/propionate/ acetate (SBWW) to a single, simple carbon source (acetate) and then back to the more complex feed, the reactor performance remained stable throughout, as demonstrated by the constant level of COD removal and gas production (Fig. 1). COD removal efficiency was generally between 97 

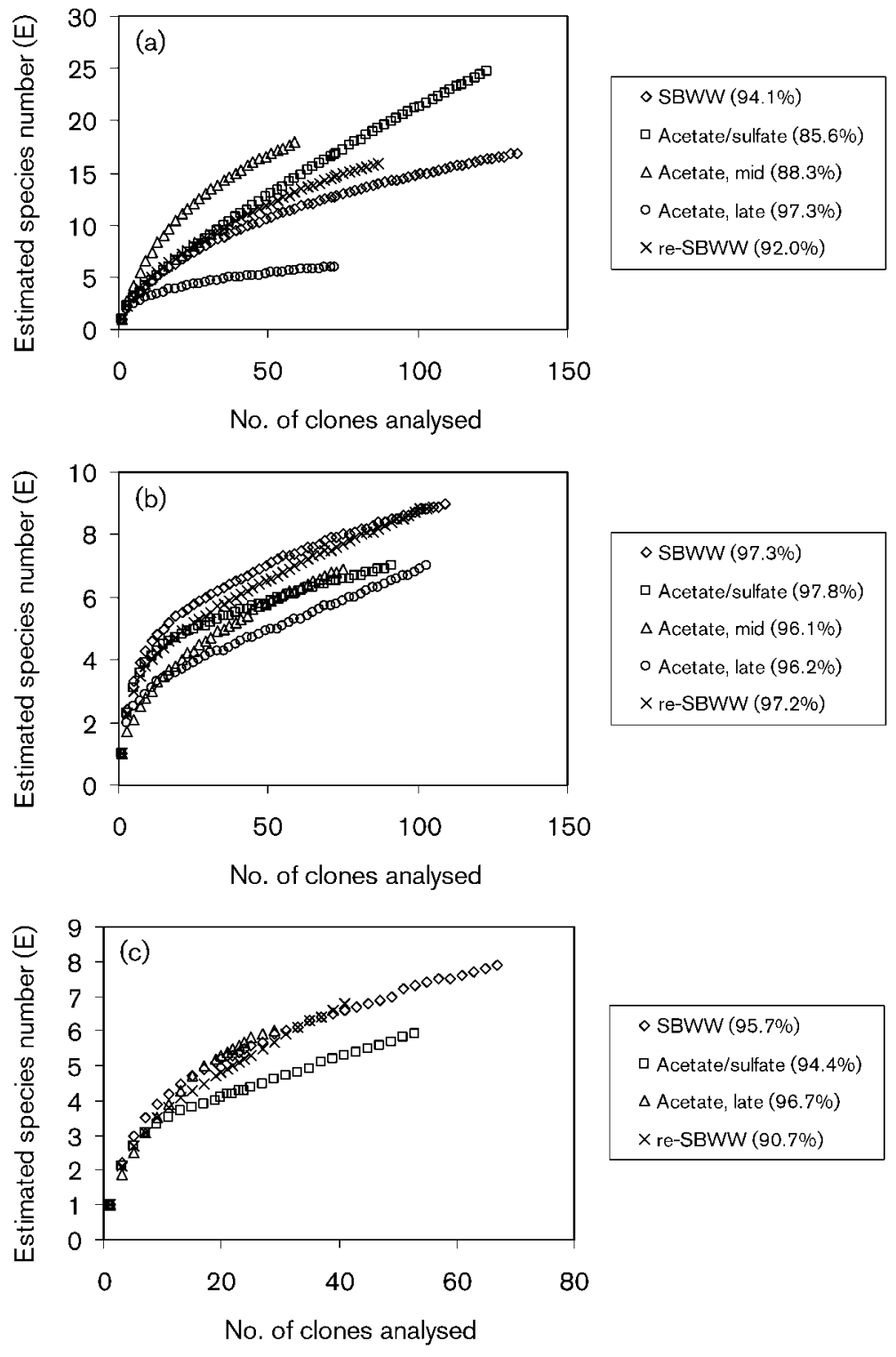

Fig. 3. Rarefaction analysis of clone libraries. Results of rarefaction analysis of $16 \mathrm{~S}$ rRNA gene clones (a), mcrA gene clones (b) and $d s r A B$ gene clones (c). The number in parentheses represents the clone coverage by the log normal method (see Methods for details). and $99 \%$ of the input COD of $5600 \mathrm{mg} \mathrm{l}^{-1}$. A notable decrease in removal efficiency was seen just after transition from acetate-only feed in phase 3 to phase 4 regrowth on SBWW (days 197-205 of the experiment, Fig. 1), suggesting that this transition was the most stressful one in terms of overall reactor performance, although COD removal efficiency still exceeded $90 \%$ during this time.

Although the reactor functioned in a stable manner, the microbial populations changed during the experiment. Our $16 \mathrm{~S}$ rRNA gene, $m c r A$ and $d s r A B$ clone libraries all showed a general decrease in diversity during the transition from SBWW to acetate alone (Fig. 4). This was supportive of our original hypothesis that diversity would decrease due to the loss of a higher trophic level, i.e. the syntrophs and fermentative bacteria that normally convert ethanol and propionate into hydrogen and acetate utilized by the methanogens. However, there was a very large transient increase in diversity noted in our $16 \mathrm{~S}$ rRNA gene data for the 2 month sampling on acetate alone (mid) (value= 3.63), almost entirely related to increased numbers of OTU within the bacterial populations (Fig. 4, bacterial component of the Shannon-Wiener index). Although our rarefaction analysis indicated that we captured the majority of the diversity of organisms present with our cloning analysis (Fig. 3), the maximum saturation of potential species was never achieved for phase 2 transitions from SBWW to acetate/sulfate and acetate alone. This is consistent with prior studies in bioreactors showing large increases in rare populations of bacterial species as the result of change or perturbation (Delbes et al., 2000, 2001; Zumstein et al., 2000; Fernandez et al., 1999, 2000; LaPara et al., 2002; Pender et al., 2004). Thus, the transient increase in diversity levels that was noted might be more reflective of the true complexity of bacterial populations within the structured biogranular communities. 

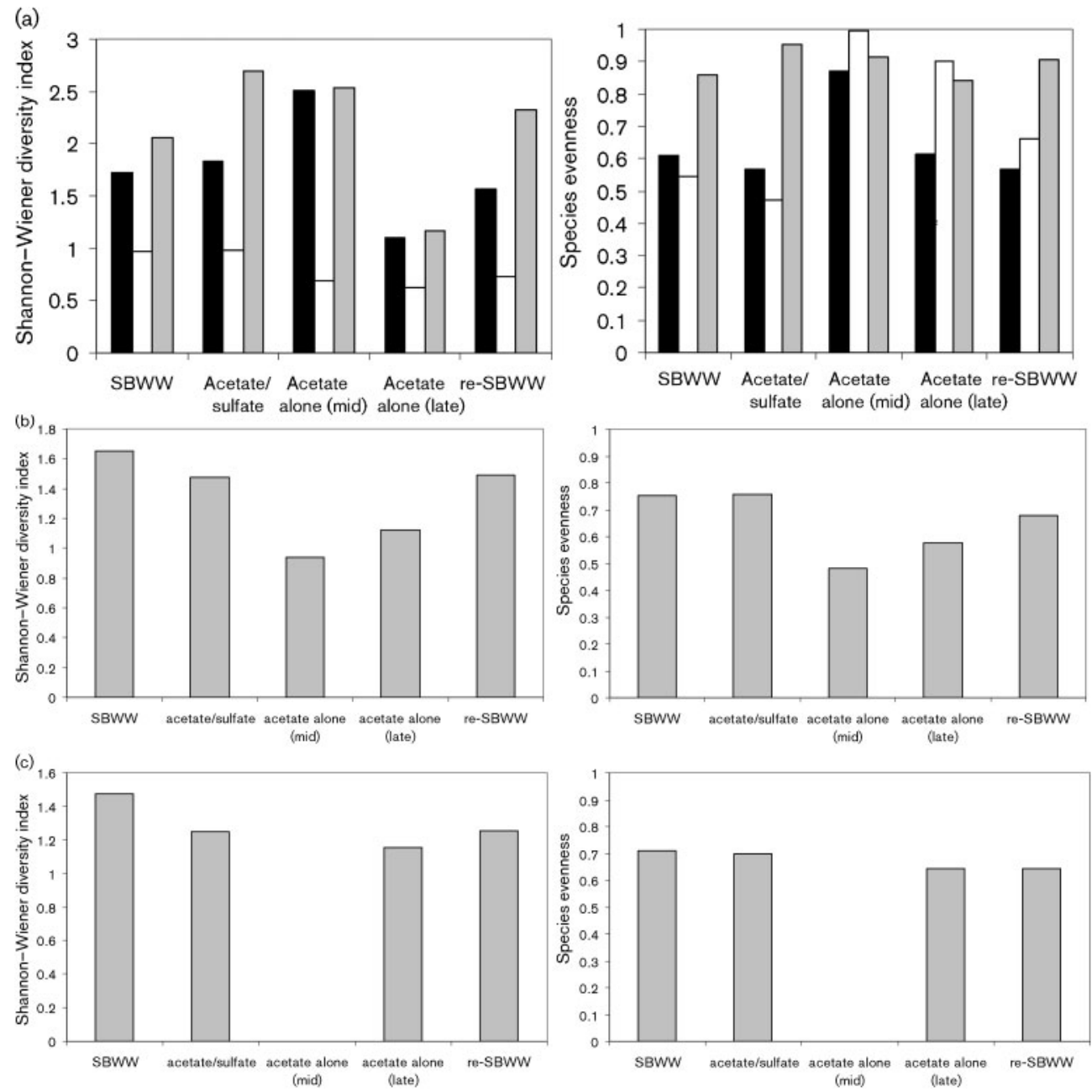

Fig. 4. Changes in diversity and species evenness with treatment. Changes in Shannon-Wiener diversity index and species evenness are shown for 16S rRNA (a), mcrA (b) and dsrAB (c) genes as a result of changes in substrate feed. The relative contributions of bacterial (grey bars) and archaeal (white bars) species to the 16S rRNA gene (a) are shown (black bars, total).

The complete degradation of ethanol/propionate/acetate to $\mathrm{CO}_{2}$ and $\mathrm{CH}_{4}$ is achieved by a microbial community consisting of methanogenic archaea and fermenting and acetogenic bacteria. Ethanol can be degraded syntrophically by Thermoanaerobium brockii, Peleobacter strains and certain ethanol-oxidizing Desulfovibrio strains (Ben-Bassat et al., 1981; Kremer et al., 1988; Schink 1992a, b). From our 16S rRNA gene libraries, it was not obvious which organisms were involved in the syntrophic degradation of ethanol despite being an important component of the feed (75\% of COD). Although not present in our 16S rRNA gene libraries, our $d s r A B$ libraries showed that sequences related to Desulfovibrio (deltaproteobacteria) were present in the granules. Several $d s r A B$ OTUs decreased after switching the feed to acetate alone, but seemed to be reestablished after switching back to SBWW. This suggests that at least members of the species Desulfovibrio must have been involved in the syntrophic degradation of ethanol.
Methanogens clearly dominated the 16S rRNA gene clone libraries at all time points, but a clear distinction must be made between the two functional groups of methanogens: hydrogenotrophic (hydrogen/formate-consuming) and acetotrophic (acetate-consuming) methanogens. A shift was observed in the populations when the feed shifted from SBWW to acetate alone. Hydrogenotrophic methanogens (HTM) gave way to acetotrophic methanogens (ATM) and sequences from the latter became the dominant sequences in the $16 \mathrm{~S}$ rRNA gene clone libraries. This can be explained by the fact that ethanol and propionate were omitted from the feed and thus no more hydrogen or formate was being produced that could be used by HTMs, resulting in ATMs taking over the clone libraries. This shift in functionality (hydrogenvs acetate-consuming) was expected to happen and has been shown to occur in other studies (Delbes et al., 2000, 2001). 
Several syntrophic propionate-oxidizing bacteria have been described, such as Smithella propionica, Desulfotomaculum thermobenzoicum, Pelotomaculum thermopropionicum and Syntrophobacter species (De Bok et al., 2001; Imachi et al., 2002; Plugge et al., 2002). One OTU related to S. wolinii was observed in almost all of our 16S rRNA gene libraries. The OTU disappeared in the acetate alone (late) feed but the population re-established itself as soon as the feed was switched back to the original feed with propionate. This clearly showed the involvement of Syntrophobacter species in the syntrophic degradation of propionate in the biogranules. Many other studies have shown that Syntrophobacter species are key organisms for the syntrophic oxidation of propionate in biogranules (Boone \& Bryant, 1980; Wallrabenstein et al., 1995; Harmsen et al., 1998). However, it cannot be ruled out that other syntrophic propionate-oxidizing bacteria are of importance as well.

OTUs related to the GNS bacteria (Chloroflexi group) were relatively well-represented in our 16S rRNA gene libraries. Several populations restored themselves or appeared as soon as the feed was switched back to SBWW in phase 4 of our experiment (with ethanol and propionate) after the disturbance with acetate alone. This suggests that GNS bacteria might play a role in the degradation of these compounds and we therefore propose that GNS bacteria are identified as potentially syntrophic bacteria. GNS bacteria have been shown to be present in many bioreactors, but only a few have been isolated, and their exact eco-physiological role in biogranules remains largely unknown. Prior research using FISH probes specific to GNS has shown that these organisms tend to inhabit the outermost portions of biogranules (Sekiguchi et al., 1999), and one isolate cultivated from a thermophilic reactor biogranule (Sekiguchi et al., 2001b) was able to grow on limited substrates (sucrose, glucose or arabinose in the presence of yeast extract), producing hydrogen, acetate and $\mathrm{CO}_{2}$. Interestingly, growth was greatly increased in a co-culture with a hydrogen-consuming methanogen (Methanothermobacter thermautotrophicus), suggesting a syntrophic relationship with methanogens. However, to understand their exact eco-physiological role and significance in biogranules, further research is needed.

Interestingly, our $m c r A$ libraries showed a different picture compared with our 16S rRNA gene libraries. In these libraries, only mcrA sequences from HTM were obtained, excluding sequences from ATM. Although acetate was only a small fraction of the original feed ( $15 \%$ of COD), as an intermediate from ethanol and propionate it is produced in significant quantities that can almost equal $100 \%$ of COD intrinsically. Furthermore, when the feed was switched to acetate alone ( $100 \%$ of COD) a clear increase in $16 \mathrm{~S}$ rRNA gene clones related to the acetate-consuming Methanosaeta species was observed, but this amplification was not reflected in the $m c r A$ libraries. One possibility is the bias of the mcrA primers towards the mcrA of HTM. A recent study of $m c r A$ genes using T-RFLP with defined mixtures of methanogenic cultures showed a bias toward Methanobacterium sp., and against Methanosaeta sp., but different $m c r A$ primers were used in that analysis compared with our analysis (Lueders \& Friedrich, 2003). These authors speculated that the degenerate nature of the primers themselves (similar to our primers) may have contributed to the bias. The dominance of HTM in our $m c r A$ libraries showed that the HTM had a great deal of resilience during and after the disturbance of their substrate feed. It is unlikely that the HTM were able to consume acetate because all of the OTUs were closely related to Methanobacterium species, specialists known to consume only hydrogen and formate.

Perhaps the continued presence of HTM under acetateonly feed conditions can be explained by the fact that some of the acetate may be oxidized by acetate-oxidizing syntrophs to hydrogen and carbon dioxide, which then can be utilized by the HTM. Syntrophic acetate oxidation was first described for a moderately thermophilic bacterium, strain AOR (Lee \& Zinder, 1988; Zinder \& Koch, 1984), and later, other syntrophic acetate-oxidizers have been described (Hattori et al., 2000; Schnürer et al., 1996). Although syntrophic acetate oxidation at $37{ }^{\circ} \mathrm{C}$ is presumed to be of minor importance in the biogranules because of the superior competitive advantages of acetateconsuming specialists like Methanosaeta species, this process may take place in biogranules. Studies have shown that different chemostat dilution rates or stress conditions caused a metabolic pathway shift between aceticlastic and non-aceticlastic methanogenesis in the degradation of acetate (Schnürer et al., 1994; Shigematsu et al., 2003; Wagner et al., 1998). In our experiment, the switch from a complex (ethanol/propionate/acetate) to a simple feed (acetate + sulfate and acetate alone) perhaps stressed the ATM enough to make syntrophic acetate oxidation possible, or revealed its potential because microbial groups from other trophic levels started to disappear from the biogranules.

We chose DNA cloning and sequence analysis of three independent genes - rRNA gene, $m c r A$ and $d s r A$ - to probe the structure of the microbial communities in UASB biogranules in response to a change in reactor feed from the complex SBWW to acetate alone. Our results showed that the microbial communities changed in direct response to the feed changes, while overall reactor function remained relatively constant. Methanogen numbers dominated the $16 \mathrm{~S}$ clone libraries, while a number of rare individual bacterial species were identified during the transition to simpler reactor feed, resulting in transitory increased diversity levels.

Further research would be required to determine the functional role of hydrogen-utilizing methanogens versus acetoclastic methanogens in the UASB biogranules in response to the change in reactor feed. An examination of mRNA changes or FISH microautoradiography analysis with radiolabelled substrates might determine whether 
acetoclastic methanogens are more active during the transition to acetate feed, as indicated by our $16 \mathrm{~S}$ data, or whether hydrogen-utilizing methanogens remain active with all feeds, as indicated by our mcrA data. Aside from the interesting possibility that syntrophic acetate oxidation involving many bacterial groups and hydrogen-utilizing methanogens may be involved in the conversion of acetate to methane in biogranules, the question could also have important implications for the operation of UASB reactors in general. As a near-neutral $\mathrm{pH}$ is one of the critical factors for reactor performance and granule integrity, different strategies (for example bioaugmentation) might be utilized to prevent build-up of volatile fatty acids and acid formation if hydrogen-utilizing methanogens were mainly responsible for methane formation.

Our clone data also indicated that the individual treatment time periods may not have been sufficient for full stabilization of the communities to equilibrium, as shown by the identification of different species at the 2 month versus 3 month time points on acetate alone. The patterns noted in our DNA-based analysis could in part also be reflective of residual DNA from dead or decaying biomass in the biogranules in response to the changes in reactor feed. Our study did not specifically address this issue, although we assumed that the processes of death and growth of various groups were occurring in response to reactor feed changes. Therefore, an analysis of mRNA would help delineate not only which archaeal and bacterial groups are most active in the biogranules but also which are growing and dying in response to reactor feed changes.

\section{ACKNOWLEDGEMENTS}

The work was supported by a grant from Laboratory Directed Research and Development Program (LDRD) of Pacific Northwest National Laboratory (PNNL). Pacific Northwest National Laboratory is operated by Battelle Memorial Institute for the US Department of Energy through contract DE-AC06-76RLO 1830.

\section{REFERENCES}

Ben-Bassat, A., Lamed, R. \& Zeikus, J. G. (1981). Ethanol production by thermophilic bacteria: metabolic control of end product formation in Thermoanaerobium brockii. J Bacteriol 146, 192-199.

Boone, D. R. \& Bryant, M. P. (1980). Propionate-degrading bacterium, Syntrophobacter wolinii sp. nov. gen. nov., from methanogenic ecosystems. Appl Environ Microbiol 40, 626-632.

Briones, A. \& Raskin, L. (2003). Diversity and dynamics of microbial communities in engineered environments and their implications for process stability. Curr Opin Biotechnol 14, 270-276.

Davey, M. E. \& O'Toole, G. A. (2000). Microbial biofilms: from ecology to molecular genetics. Microbiol Mol Biol Rev 64, 847-867.

De Bok, F. A. M., Stams, A. J. M., Dijkema, C. \& Boone, D. R. (2001). Pathway of propionate oxidation by a syntrophic culture of Smithella propionica and Methanospirillum hungatei. Appl Environ Microbiol 67, $1800-1804$
Delbes, C., Moletta, R. \& Godon, J. J. (2000). Monitoring of activity dynamics of an anaerobic digester bacterial community using $16 \mathrm{~S}$ rRNA polymerase chain reaction-single-strand conformation polymorphism analysis. Environ Microbiol 2, 506-515.

Delbes, C., Moletta, R. \& Godon, J. J. (2001). Bacterial and archaeal 16S rDNA and 16S rRNA dynamics during an acetate crisis in an anaerobic digestor ecosystem. FEMS Microbiol Ecol 35, 19-26.

Díaz, E., Amils, R. \& Sanz, J. L. (2003). Molecular ecology of anaerobic granular sludge grown at different conditions. Water Sci Technol 48, $57-64$.

Fernandez, A., Huang, S., Seston, S., Xing, J., Hickey, R., Criddle, C. \& Tiedje, J. (1999). How stable is stable? Function versus community composition. Appl Environ Microbiol 65, 3697-3704.

Fernandez, A. S., Hashsham, S. A., Dollhopf, S. L., Raskin, L., Glagoleva, O., Dazzo, F. B., Hickey, R. F., Criddle, C. S. \& Tiedje, J. M. (2000). Flexible community structure correlates with stable community function in methanogenic bioreactor communities perturbed by glucose. Appl Environ Microbiol 66, 4058-4067.

Ferry, J. G., Smith, P. H. \& Wolfe, R. S. (1974). Methanospirillum, a new genus of Methanogenic bacteria, and characterization of Methanospirillum hungatii sp. nov. Int J Syst Bacteriol 24, 465-469.

Hales, B. A., Edwards, C., Ritchie, D. A., Hall, G., Pickup, R. W. \& Saunders, J. R. (1996). Isolation and identification of methanogenspecific DNA from blanket bog peat by PCR amplification and sequence analysis. Appl Environ Microbiol 62, 668-675.

Harmsen, H. J. M., Van Kuijk, B. L. M., Plugge, C. M., Akkermans, A. D. L., De Vos, W. \& Stams, A. J. M. (1998). Syntrophobacter fumaroxidans sp. nov., a syntrophic propionate-degrading sulfatereducing bacterium. Int J Syst Bacteriol 48, 1383-1387.

Hattori, S., Kamagata, Y. \& Shoun, H. (2000). Thermacetogenium phaeum gen. nov., sp. nov., a strictly anaerobic, thermophilic syntrophic acetate-oxidizing bacterium. Int J Syst Evol Microbiol 50, 1601-1609.

Hurlbert, S. H. (1971). The nonconcept of species diversity: a critique and alternative parameters. Ecology 52, 577-586.

Imachi, H., Sekiguchi, Y., Kamagata, Y., Hanada, S., Ohashi, A. \& Harada, H. (2002). Pelotomaculum thermopropionicum gen. nov., sp nov., an anaerobic, thermophilic, syntrophic propionate-oxidizing bacterium. Int J Syst Evol Microbiol 52, 1729-1735.

Kotelnikova, S., Macario, A. \& Pedersen, K. (1998). Methanobacterium subterraneum sp. nov., a new alkaliphilic, eurythermic and halotolerant methanogen isolated from deep granitic groundwater. Int J Syst Bacteriol 48, 357-367.

Kremer, D. R., Nienhuis-Kuiper, H. E. \& Hansen, T. A. (1988). Ethanol dissimilation in Desulfovibrio. Arch Microbiol 150, 552-557.

Lane, D. J., Pace, B., Olsen, G. J., Stahl, D. A., Sogin, M. L. \& Pace, N. R. (1985). Rapid determination of $16 S$ ribosomal RNA sequences for phylogenetic analyses. Proc Natl Acad Sci U S A 82, 6955-6959.

LaPara, T. M., Nakatsu, C. H., Pantea, L. M. \& Alleman, J. E. (2002). Stability of the bacterial communities supported by a seven-stage biological process treating pharmaceutical wastewater as revealed by PCR-DGGE. Water Res 36, 638-646.

Lee, M. J. \& Zinder, S. H. (1988). Isolation and characterization of a thermophilic bacterium which oxidizes acetate in syntrophic association with a methanogen and which grows acetogenically on $\mathrm{H}_{2}-\mathrm{CO}_{2}$. Appl Environ Microbiol 54, 124-129.

Lettinga, G. (1995). Anaerobic digestion and waste-water treatment systems. Antonie Van Leeuwenhoek 67, 3-28.

Ludwig, W., Strunk, O., Westram, R., Richter, L., Meier, H., Yadhukumar, Buchner, A., Lai, T., Steppi, S. \& other authors 
(2004). ARB: a software environment for sequence data. Nucleic Acids Res 32, 1363-1371.

Lueders, T. \& Friedrich, M. W. (2003). Evaluation of PCR amplification bias by terminal restriction fragment length polymorphism analysis of small-subunit rRNA and $m c r A$ genes by using defined template mixtures of methanogenic pure cultures and soil DNA extracts. Appl Environ Microbiol 69, 320-326.

Mullins, T. D., Britschgi, T. B., Krest, R. L. \& Giovannoni, S. J. (1995). Genetic comparisons reveal the same unknown bacterial lineages in Atlantic and Pacific bacterioplankton communities. Limnol Oceanogr 40, 148-158.

Muyzer, G., Wall, E. C. D. \& Uitterlinden, A. G. (1993). Profiling of complex microbial populations by denaturing gradient gel electrophoresis analysis of polymerase chain reaction-amplified genes coding for 16S rRNA. Appl Environ Microbiol 59, 695-700.

Pender, S., Toomey, M., Carton, M., Eardly, D., Patching, J. W. C., Colleran, E. \& O'Flaherty, V. (2004). Long-term effects of operating temperature and sulphate addition on the methanogenic community structure of anaerobic hybrid reactors. Water Res 38, 619-630.

Plugge, C. M., Balk, M. \& Stams, A. J. M. (2002). Desulfotomaculum thermobenzoicum subsp. thermosyntrophicum subsp. nov., a thermophilic, syntrophic, propionate-oxidizing, spore-forming bacterium. Int J Syst Evol Microbiol 52, 391-399.

Schink, B. (1992a). Syntrophism among prokaryotes. In The Prokaryotes. Edited by A. Balows, H. G. Trüper, M. Dworkin, W. Harder \& K. H. Schleifer. New York: Springer.

Schink, B. (1992b). The genus Pelobacter. In The Prokaryotes. Edited by A. Balows, H. G. Trüper, M. Dworkin, W. Harder \& K. H. Schleifer. New York: Springer.

Schink, B. (1997). Energetics of syntrophic cooperation in methanogenic degradation. Microbiol Mol Biol Rev 61, 262-280.

Schnürer, A., Houwen, F. P. \& Svensson, B. H. (1994). Mesophilic syntrophic acetate oxidation during methane formation by a triculture at high ammonium concentration. Arch Microbiol 162, 70-74.

Schnürer, A., Schink, B. \& Svensson, B. H. (1996). Clostridium ultunense sp. nov., a mesophilic bacterium oxidizing acetate in syntrophic association with a hydrogenotrophic methanogenic bacterium. Int J Syst Bacteriol 46, 1145-1152.

Sekiguchi, Y., Kamagata, Y., Nakamura, K., Ohashi, A. \& Harada, H. (1999). Fluorescence in situ hybridization using 16S rRNA-targeted oligonucleotides reveals localization of methanogens and selected uncultured bacteria in mesophilic and thermophilic sludge granules. Appl Environ Microbiol 65, 1280-1288.

Sekiguchi, Y., Kamagata, Y. \& Harada, H. (2001a). Recent advances in methane fermentation technology. Curr Opin Biotechnol 12, 277282.

Sekiguchi, Y., Takahashi, H., Kamagata, Y., Ohashi, A. \& Harada, H. (2001b). In situ detection, isolation, and physiological properties of a thin filamentous microorganism abundant in methanogenic granular sludges: a novel isolate affiliated with a clone cluster, the green nonsulfur bacteria, subdivision I. Appl Environ Microbiol 67, 5740-5749.

Shannon, C. E. \& Weaver, W. (1948). Mathematical Theory of Communications. Urbana: University of Illinois Press.

Sheffield, V. C., Cox, D. R., Lerman, L. S. \& Myers, R. M. (1989). Attachment of a 40-base-pair $\mathrm{G}+\mathrm{C}$-rich sequence to genomic DNA fragments by the polymerase chain reaction results in improved detection of single-base changes. Proc Natl Acad Sci U S A 86, 232236.

Shigematsu, T., Tang, Y. Q., Kawaguchi, H., Ninomiya, K., Kijima, J., Kobayashi, T., Morimura, S. \& Kida, K. (2003). Effect of dilution rate on structure of a mesophilic acetate-degrading methanogenic community during continuous cultivation. J Biosci Bioeng 96, 547558.

Tipper, J. C. (1979). Rarefaction and rarefiction - the use and abuse of a method in paleoecology. Paleobiology 5, 423-434.

Wagner, M., Roger, A. J., Flax, J. L., Brusseau, G. A. \& Stahl, D. A. (1998). Phylogeny of dissimilatory sulfite reductases supports an early origin of sulfate respiration. J Bacteriol 180, 2975-2982.

Wallrabenstein, C., Hauschild, E. \& Schink, B. (1995). Syntrophobacter pfennigii sp. nov., new syntrophically propionateoxidizing anaerobe growing in pure culture with propionate and sulfate. Arch Microbiol 164, 346-352.

Wu, M. M., Criddle, C. S. \& Hickey, R. F. (1995). Mass transfer and temperature effect on substrate utilization in brewery granules. Biotechnol Bioeng 46, 465-475.

Zinder, S. H. \& Koch, M. (1984). Non-acetoclastic methanogenesis from acetate: acetate oxidation by a thermophilic syntrophic coculture. Arch Microbiol 138, 263-272.

Zumstein, E., Moletta, R. \& Godon, J. J. (2000). Examination of two years of community dynamics in an anaerobic bioreactor using fluorescence polymerase chain reaction (PCR) single-strand conformation polymorphism analysis. Environ Microbiol 2, 69-78.

Edited by: H. Daims 